\title{
ROBOT PENJELAJAH BERODA AUTONOMOUS
}

\author{
Joni Fat dan Riski Sanderson \\ Program Studi Teknik Elektro Jurusan Teknologi Industri \\ Fakultas Teknik Universitas Tarumanagara \\ e-mail: jonif@ft.untar.ac.id
}

\begin{abstract}
The wheeled robot design consists of various modules with their own functionalities. We chose the components based on theirs specification, autonomous functionality, and in theirs prices. We assembled these components as modules. The modules in this design are power supply module, processing module which is used ATMega 328 microcontroller, distance sensor module, line sensor module, wireless communication module, motor driver module and actuator module which is used DC motor. System performance indicated with: Able to follow square, triangle, synes conture and stopping ability. Experiment shawed that all of the modules worked as design. The robot could navigate according to contours autonomously. We tested by using a display module. We gave inputs and then feeded to processing module through bluetooth. From the experiment, it can be concluded that the robot which was using wall following method could be controlled well. The PID controller performed well so the navigation could be stable. The stable condition was achieved under 3 seconds. But the performance criteria had not been achieved because the maximum overshoot was $41.2 \%$ which was far from the limit of $10 \%$.
\end{abstract}

Keywords: autonomous, ATMega, contour, PID, wall following.

\section{PENDAHULUAN}

Robot yang dirancang berupa robot beroda yang memiliki pengendali kecepatan pada aktuatornya yang berupa dua motor DC. Aktuator ini digunakan selain untuk bergerak juga untuk penentuan posisi dalam menjelajah. Metode penjelajahan yang digunakan adalah metode wall following sesuai dengan masukan jarak robot ke dinding [1]. Sistem ini memungkinkan robot mengikuti dinding tanpa menabrak dinding dengan berbagai kontur seperti berbentuk persegi, segitiga, dan sinus. Ada persyaratan minimal yang pelu diperhatikan, antara lain ukuran robot dan dinding, serta jarak minimal antara robot ke dinding. Persyaratan minimal ini harus terpenuhi agar robot dapat melakukan penjelajahan pada dinding.

Sistem yang dirancang terdiri dari dua modul, yaitu modul yang dirancang dan modul yang tidak dirancang. Modul-modul yang dirancang terdiri dari modul catu daya, modul pemroses, modul perangkat lunak pengontrol, modul pendeteksi garis, modul tampilan dan masukan, dan modul aktuator. Modul-modul yang tidak dirancang berupa modul komputer, modul pendeteksi jarak, modul komunikasi, dan modul driver. Selain itu, robot autonomous ini juga tidak dapat melakukan penjelajahan bila ada halangan pada jalur yang dilewatinya, robot hanya mampu menjelajah mengikuti dinding sebelah kanan, dan jarak perubahan kontur dinding harus lebih besar dari pada ukuran lebar robot ditambah dua kali nilai jarak robot ke dinding yang menjadi acuannya.

Robot autonomous ini memiliki spesifikasi sebagai berikut: robot menggunakan dua motor DC, catu daya yang diperlukan berupa catu daya dengan tegangan keluaran $+5 \mathrm{~V}_{\mathrm{DC}}$, robot memiliki satu sensor jarak dan garis, pemroses robot berupa satu mikrokontroler 8-bit, serta dimensinya adalah $135 \mathrm{~mm}$ x $135 \mathrm{~mm}$ x $70 \mathrm{~mm}$.

\section{METODE PENELITIAN \\ Komponen-Komponen Utama}

\section{Mikrokontroler}

Mikrokontroler yang digunakan adalah ATMega 328 seperti yang ditunjukkan oleh Gambar 1, yang digunakan untuk mengendalikan kecepatan motor DC dan penentuan posisi robot dalam bernavigasi dengan menggunakan algoritma PID. Nilai posisi ditentukan sesuai dengan hasil komunikasi dengan pemroses. Selain itu, mikrokontroler ini juga digunakan untuk membaca sensor seperti sensor garis dan sensor jarak. Mikrokontroler ini dipilih karena memiliki jumlah jalur 
input/output yang tidak terlalu banyak atau sekitar 23 jalur I/O, yang mana jumlah tersebut telah lebih dari cukup untuk aplikasi ini. Dengan jumlah demikian, ukuran modul menjadi tidak terlalu besar.

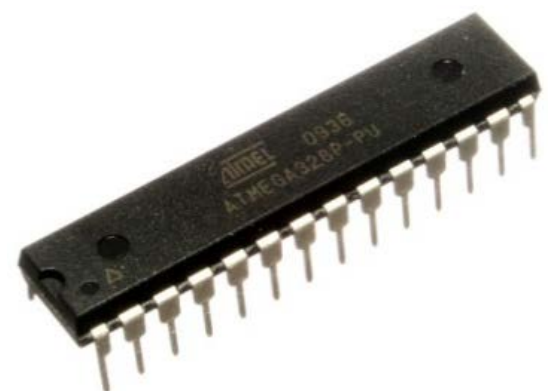

Gambar 1. Bentuk fisik DIP ATMega328

Mikrokontroler ini juga memiliki dua buah timer/counter 8-bit yang digunakan untuk menghitung satu periode dari algoritma PID, satu buah timer/counter 16-bit yang digunakan untuk membangkitkan dua sinyal PWM untuk kedua motor, ADC untuk membaca nilai analog dari sensor garis, dan Universal Synchronous and Asynchronous serial Receiver and Transmitter (USART) untuk berkomunikasi dengan pemroses. Mikrokontroler ini mempunyai memori untuk menampung program (In-System Self-Programmable Flash program memory) sebesar 32 KB, dan memori untuk menampung parameter data pada Electrically Erasable Programmable Read-Only Memory (EEPROM) sebesar $1 \mathrm{~KB}$, serta Static Random-Access Memory (SRAM) sebesar $2 \mathrm{~KB}$. Ukuran memori yang disediakan cukup untuk program pengendali.

\section{Sensor Ultrasonik}

Sensor ultrasonik yang digunakan adalah SRF-04. Sensor ini menggunakan sonar ultrasonik dengan frekuensi $40 \mathrm{KHz}$ untuk membaca nilai jarak yang terukur dengan periode pembacaan sensor sekitar $65 \mathrm{~ms}$ [2]. Objek yang diukur adalah dinding. Nilai jarak ini digunakan sebagai nilai PV dari algoritma PID. Sensor SRF-04 dipilih karena memiliki jarak pengukuran minimal $2 \mathrm{~cm}$, dan jarak pengukuran maksimal 10,7 m [3].

Selain itu, sensor ini memiliki lebar tembakan atau lebar pembacaan sensor selebar $55^{\circ}$. SRF04 memiliki lima pin, yaitu pin $5 \mathrm{~V}$, echopulseoutput, triggerpulseinput, donotconnect, dan $0 \mathrm{~V}$ ground. Dari lima pin, empat pin perlu dihubungkan ke pengendali (kecuali do not connect). Pin input dan output dari SRF dibedakan menjadi dua pin tersendiri, sehingga memudahkan melakukan pengontrolan dan pembacaan SRF. Bentuk dari sensor jarak SRF-04 dapat dilihat pada Gambar 2. Sensor ini memiliki dua tranduser, pengirim atau pemancar ultrasonik dan penerima.

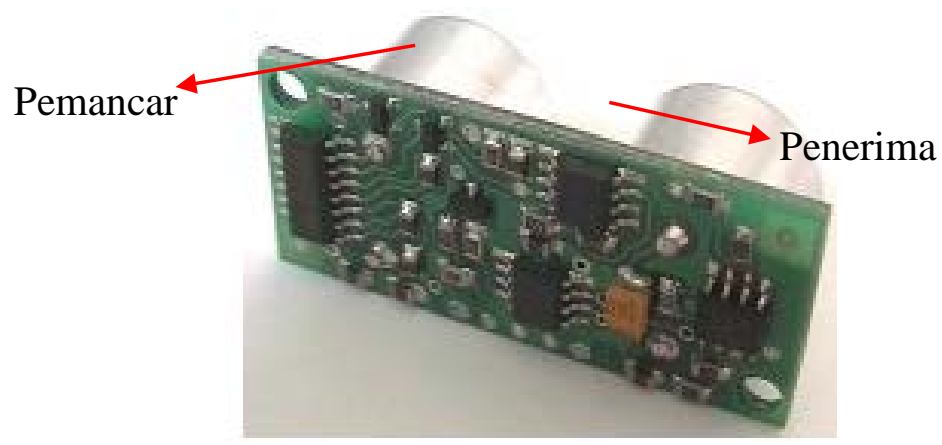

Gambar 2. Sensor SRF-04

\section{BPW 43}

BPW43 adalah sensor photodioda dengan pin berukuran standar T-13/4 (berdiameter $5 \mathrm{~mm}$ ) atau sejenis dengan photodetector yang mengonversi besaran cahaya menjadi besaran listrik yang 
ditunjukkan oleh gambar. Sensor ini digunakan untuk mendeteksi garis pada lantai. Dengan membaca intensitas cahaya yang terpantul dari lantai, warna dari lantai dapat dibaca oleh sensor ini. Untuk pendukung, digunakan Light Emitting Diode (LED) berwarna putih sebagai sumber cahayanya. Penggunaan LED berwarna putih dikarenakan warna lantai adalah putih dan garis adalah hitam sehingga sangat efektif bila menggunakan LED berwarna putih.

Alasan lain pemilihan photodioda tersebut dikarenakan lensa pelindung photodioda ini terbuat dari epoxy dengan warna transparan, sehingga sensor ini sensitif terhadap cahaya tampak dan radiasi infrared. Dengan demikian photodioda ini dapat membaca pemantulan intensitas cahaya yang dipantulkan dari LED berwarna putih. Selain itu, sensor ini memiliki waktu respon yang sangat cepat dengan risetime sekitar $4 \mathrm{~ns}$, dan fall time sekitar 4 ns pada tegangan rangkaian sekitar $10 \mathrm{~V}$ dengan panjang gelombang $820 \mathrm{~nm}$. Bentuk dari BPW43 dapat dilihat pada Gambar 3.

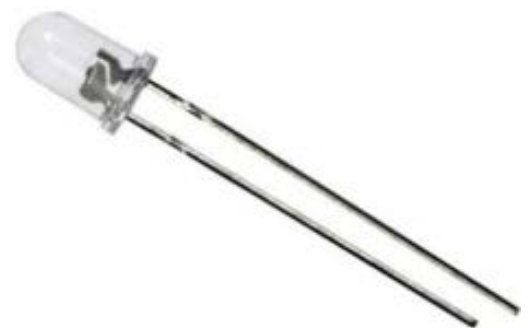

Gambar 3. Bentuk fisik sensor intensitas cahaya BPW 43 [4]

\section{IC LM7805}

IC LM7805 merupakan IC fixed positive-voltage regulator yang dapat meregulasi tegangan DC dari level tegangan yang lebih tinggi ke level tegangan 5 VDC. Walau pun dapat menurunkan tegangan ke $5 \mathrm{~V}_{\mathrm{DC}}$, IC ini tetap memiliki batasan tegangan masukan. Tegangan masukan harus minimal $7 \mathrm{~V}_{\mathrm{DC}}$ dan maximal $25 \mathrm{~V}_{\mathrm{DC}}$. Jika tegangan masukan kurang dari $7 \mathrm{~V}_{\mathrm{DC}}$, maka keluarannya akan kurang dari $5 \mathrm{VDC}_{\mathrm{DC}}$, dan jika tegangan berlebih akan merusak regulator ini. IC ini dapat mengeluarkan arus hingga 1,5 A. Jika terjadi hubung singkat, IC ini dapat membatasi arus yang melewatinya.

Alasan memilih IC ini karena suplai daya untuk sistem berasal dari baterai Lithium-Polymer (Li-Po) 3S dengan tegangan keluaran minimal sebesar 11,1 $\mathrm{V}_{\mathrm{DC}}$ dan maksimal sebesar 12,6 $\mathrm{V}_{\mathrm{DC}}$, dan rangkaian sistem memerlukan tegangan sebesar $5 \mathrm{~V}_{\mathrm{DC}}$, sehingga regulator ini cocok digunakan dalam sistem ini seperti mikrokontroler, sensor, motor, dan elektronik lainnya.

Untuk motor, dayanya akan disuplai oleh IC 7805 yang berbeda. Hal ini dikarenakan IC ini tidak sanggup menyuplai daya untuk keseluruhan, sehingga suplai daya motor dipisahkan. Alasan lain menggunakan IC ini adalah penggunaan yang cukup mudah. IC ini hanya memiliki tiga terminal, yaitu input, common, dan output. Harga IC ini relatif murah di pasaran, dibandingkan dengan IC regulator lainnya. Konfigurasi pin IC 7805 dapat dilihat pada Gambar 4.

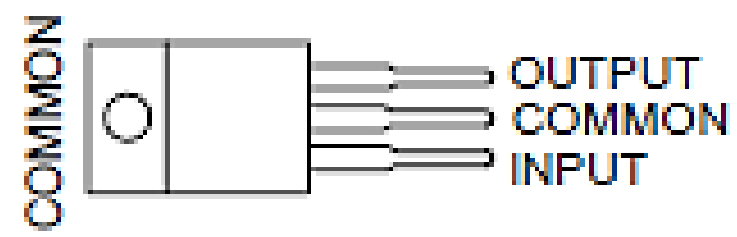

Gambar 4. IC fixed positive-voltage regulator 7805

\section{IC L293D}

IC L293D adalah IC motor driver yang merupakan quadruple high-current half-H drivers. Alasan menggunakan IC ini karena mampu mengendalikan arah arus secara bidirectional dengan keluaran arus rata-rata $600 \mathrm{~mA}$ untuk satu kanal, dan dengan arus maksimal 1,2 A. IC ini memiliki dua kanal, sehingga dapat mengendalikan dua motor secara bidirectional atau empat motor secara 
directional. Selain itu, IC ini memiliki suplai tegangan yang sangat luas untuk motor, yaitu 4,5 V hingga 36 V. Semua masukan dari IC ini kompatibel terhadap tegangan TTL. Fitur-fitur lainnya yang dimiliki IC ini antara lain: Separate Input-Logic Supply, Internal ESD Protection, Thermal Shutdown, High-Noise-Immunity Inputs, dan Output Clap Diodes for Inductive Transient Suppression. Gambar IC ini dapat dilihat pada Gambar 5.

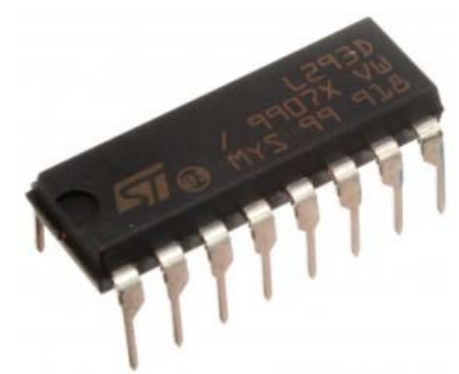

Gambar 5. Bentuk fisik DIP IC L293D [5]

\section{HC-06}

HC-06 merupakan sebuah modul komunikasi wireless bluetooth v2.0. Modul ini memungkinkan mikrokontroler terhubung dengan jaringan berbasis bluetooth. Alasan menggunakan perangkat ini karena protokol komunikasi ke perangkat ini adalah serial dengan perintah AT. Perintah AT membuat modul ini menjadi lebih gampang digunakan, karena perangkat ini dapat dikendalikan hanya dengan memanggil perintah AT saja tanpa perlu tahu cara kerja dan proses dari bluetooth. Modul ini berjalan di level tegangan $5 \mathrm{~V}_{\mathrm{DC}}$ dengan konsumsi arus sebesar $35 \mathrm{~mA}$ dengan kondisi pairing. Bentuk dari HC-06 dapat dilihat pada Gambar 6.

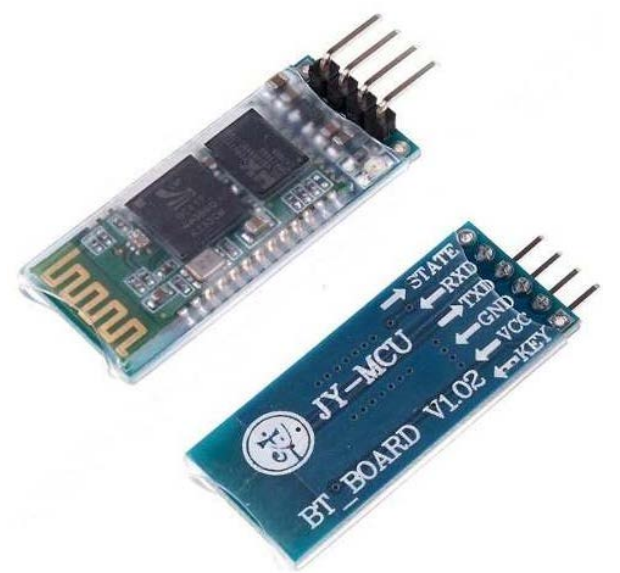

Gambar 6. Bentuk fisik HC-06 [6]

\section{HASIL DAN PEMBAHASAN}

Realisasi rancangan sistem secara keseluruhan dengan menggabungkan modul pemroses dengan modul-modul lainnya, termasuk modul mekanik. Modul utama yaitu modul pemroses akan mengendalikan dan memroses data dari sensor berupa sensor jarak dan sensor garis. Sensor jarak menggunakan I/O pin PD2 dan PD3. PD2 sebagai output dihubungkan ke trigger SRF-04 yang bertujuan untuk memberikan sinyal untuk SRF-04 agar menembakan sonar ultrasonik, hasil pembacaan pantulan sonar yang telah diproses oleh SRF-04 berupa periode sinyal high, akan diberikan melalui pin echo dari SRF-04 yang dibaca melalui pin input PD3. Pin pada SRF-04 dapat dilihat pada Gambar 7. Sinyal pembacaan dari sensor garis berupa sinyal analog dihubungkan ke pin PC1 atau ADC1 untuk dikonversi menjadi sinyal digital, sehingga data tersebut dapat diproses oleh mikrokontroler. 


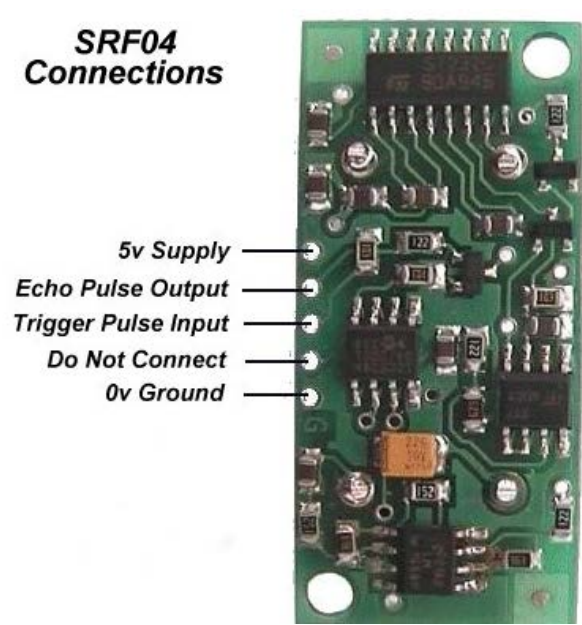

Gambar 7. Pin koneksi SRF04 [3]

Motor DC dikendalikan oleh mikrokontroler melalui motor driver L293D. Untuk dapat mengendalikan arah putaran motor, pin 1A dan 2A pada motor driver dihubungkan ke pin PD4 dan PD5 pada I/O mikrokontroler untuk motor DC sebelah kiri, dan pin 3A dan 4A pada motor driver dihubungkan ke pin PB4 dan PB5 pada I/O mikrokontroler untuk motor DC sebelah kanan. Pin 1,2EN dan pin 3,4EN pada motordriver dihubungkan pada pin PB1 (OC1A) dan PB2 (OC1B) pada mikrokontroler. Pin PB1 dan PB2 merupakan pin yang memiliki fungsi khusus yang dapat menghasilkan pulsa PWM dengan menggunakan timer 1 pada mikrokontroler. Dengan menghubungkan pin-pin tersebut, motor DC dapat dikendalikan arah putarannya beserta kecepatannya.

Modul komunikasi wireless yang menggunakan HC-06, dihubungkan ke modul pemroses pada pin PD0 (Rx) dan pin PD1 (Tx). Pin ini merupakan pin dengan fungsi khusus dari mikrokontroler yang dapat berkomunikasi serial USART. Dengan bantuan dari modul HC-06, mikrokontroler dapat berkomunikasi dengan komputer secara wireless. Ketika mikrokontroler dinyalakan, dilakukan beberapa inisialisasi seperti mengatur nilai dutycycle PWM pada motor DC sebelah kiri dan kanan dengan nilai 0, sehingga motor dalam kondisi diam. Nilai parameter-parameter yang disimpan dalam EEPROM akan dibaca dan disimpan dalam variabel yang kemudian akan digunakan dalam sistem kontrol PID. Setelah itu, program akan mencoba membaca data yang diterima dari modul komunikasi wireless. Jika terdapat data yang diterima, akan dilakukan pengecekan format data yang diterima untuk mengetahui perintah data tersebut, apakah membaca data parameter, mengubah nilai parameter, membaca nilai sensor, atau mengubah mode dari robot beroda. Jika tidak terdapat data yang diterima, maka akan dilakukan pengecekan dan menjalankan mode tersebut.

Ada tiga mode pada pengendali robot beroda, yaitu mode standby (kondisi berhenti), mode kontrol manual, dan mode kontrol PID. Mode standby merupakan mode robot dalam kondisi diam dan menunggu komunikasi data antara modul pemproses dengan komputer. Mode kontrol manual merupakan mode robot bergerak berdasarkan perintah dari komputer. Komputer mengendalikan aktifitas robot secara penuh. Mode kontrol PID merupakan mode robot bergerak berdasarkan dari sistem kontrol PID sesuai dengan parameter PID yang telah diberikan. Mode ini juga akan mengirim nilai balik ke komputer berupa nilai pembacaan sensor jarak atau nilai PV dan sensor garis. Aktifitas yang dilakukan modul mikrokontroler dapat dilihat dalam diagram alir yang ditunjukan pada Gambar 8.

Untuk mendapatkan nilai parameter PID dilakukan tuning dengan metode Ziegler-Nichols [7]. Tuning dilakukan dengan meletakan robot pada sembarang jarak disebelah kiri terhadap dinding yang rata dan lurus. Setelah itu dilakukan algoritma dari metode tuning Ziegler-Nichols, hingga mendapatkan sistem yang berosilasi dengan amplitudo konstan. Setelah mendapatkan hasil respon 
sistem, dilakukan perhitungan untuk mendapatkan konstanta $K_{p}, K_{i}$, dan $K_{d}$ dengan dengan nilai $P_{0}=$ 2,2 detik (dari $\mathrm{T}=1,4$ detik hingga $\mathrm{T}=3,6$ detik), sehingga didapat nilai $K_{p}=0,8 T_{i}=1,1$, dan $T_{d}=0,275$. Dengan demikian didapatkan nilai $K_{p}=0,8 K_{i}=0,727$, dan $K_{d}=0,22$. Sebelum memberikan input konstanta pada parameter robot, nilai integral dikali dengan $d t$ dan nilai derivative dibagi dengan $d t$, sehingga menghasilkan nilai $K_{i}=0,47$, dan $K_{d}=0,34$.

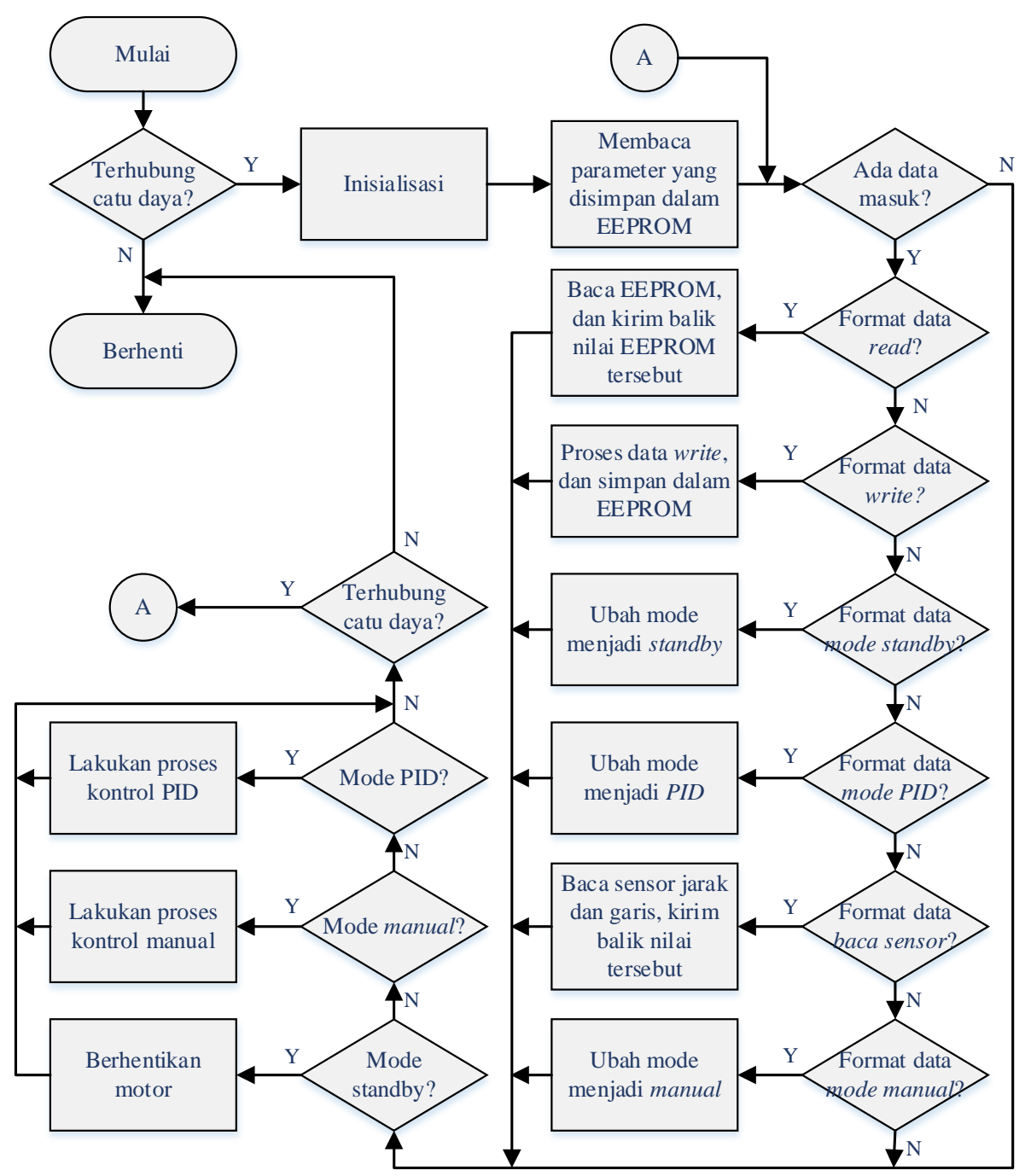

Gambar 8. Diagram alir proses modul mikrokontroler

Keluaran dari modul perangkat lunak PID merupakan kecepatan putar roda. Untuk mengonversi kecepatan roda ke nilai PWM sebesar 8 bit, dilakukan percobaan untuk mendapatkan persamaan linear nilai PWM 8 bit terhadap kecepatan roda. Percobaan yang dilakukan dengan memerikan nilai PWM dari PWM tertinggi pada kedua roda dan dilakukan pengukuran. PWM diturunkan sedikit demi sedikit, hingga kecepatan roda tidak dapat terukur lagi atau mencapai kecepatan terendah.

\section{Hasil Pengujian}

Secara umum, sistem dapat dikatakan berjalan dengan baik karena mampu mengikuti dinding dengan tidak menabrak dinding tersebut. Selain itu, robot mampu berhenti pada garis yang telah ditentukan. Hasil dari pengujian uji kasus secara keseluruhan sistem ditulis dalam bentuk tabel pengujian. Hal-hal yang akan diuji dalam pengujian kasus keseluruhan sistem dapat dilihat pada Tabel 1. 
Tabel 1. Hasil uji kasus keseluruhan sistem

\begin{tabular}{clc}
\hline No. & \multicolumn{1}{c}{ Kasus yang Diuji } & Status \\
\hline 1 & Robot mampu mengikuti kontur persegi & Berhasil \\
2 & Robot mampu mengikuti kontur segitiga & Berhasil \\
3 & Robot mampu mengikuti kontur sinus & Berhasil \\
4 & Robot dapat berhenti pada garis yang telah ditentukan & Berhasil \\
\hline
\end{tabular}

Berdasarkan dari hasil pengujian alat yang dirancang pada Tabel 1, sistem dapat bekerja dengan baik. Robot dapat mengikuti dinding sebelah kanan dengan kontur persegi, segitiga, dan sinus dengan nilai SP sesuai dengan nilai maksimal dan minimal tiap kontur. Dengan demikian, pengujian keseluruhan sistem dapat dikatakan baik.

\section{SIMPULAN}

Robot yang menggunakan metoda wall following dapat dikendalikan posisinya terhadap dinding hingga stabil dengan menggunakan PID. Keadaan stabil dapat dicapai dalam waktu kurang dari 3 detik. Akan tetapi kriteria performasi yang belum terpenuhi adalah maximum overshoot yang mencapai $41,2 \%$ atau melebihi dari kriteria yaitu maksimal $10 \%$.

\section{DAFTAR PUSTAKA}

[1] D. Floreano, J. Godjevac, A.Martinoli, F. Mondada, and D. Nicoud, Design, Control, and Applications of Autonomous Mobile Robots. Swiss Federal Institute of Technology, Lausanne, 1999. pp. 1.

[2] Element14, "Vishay BPV10NF Photodiode, Pin", 16 April 2018, Pukul 11.18 WIB, http://in.element14.com/vishay/bpv10nf/photodiode-pin/dp/1328399.

[3] SRF04 Technical Documentation, “SRF-04 - Ultra-Sonic Ranger”, 16 April 2018, Pukul 11.22 WIB, Pukul 22.02 WIB, http://www.robot-electronics.co.uk/htm/srf04tech.htm.

[4] Solarbotics, "5mm Water-clear Phototransistor", 16 April 2018, Pukul 11.33 WIB, https://solarbotics.com/product/17700/.

[5] "L293D Quadruple Half-H Drivers", 16 April 2018, Pukul 11.50 WIB, https://twinschip.com/index.php?route=themecontrol/product\&product_id=404.

[6] M. Vasilakis, Arduino automotive, "How to Program Bluetooth Module HC-06 with Arduino UNO”, 16 April 2018, Pukul 11.55 WIB, http://en.ardumotive.com/hc-06-bt-module.

[7] K. Ogata, Modern Control Engineering 4th edition. Prentice-Hall, New Jearsy, 2002. pp. 681685. 